\title{
A EdUCAÇÃo REFLEXIVA NA PóS-MOdERNIDADE: UMA REVISÃO BIBLIOGRÁFICA ${ }^{1}$
}

Jomara Brandini Gomes ${ }^{2}$

Lisete Diniz Ribas Casagrande ${ }^{3}$

Gomes JB, Casagrande LDR. A educação reflexiva na pós-modernidade: uma revisão bibliográfica. Rev Latino-am Enfermagem 2002 setembro-outubro; 10(5):696-703.

Trata-se de uma revisão bibliográfica buscando situar o ensino no momento histórico que estamos vivendo, denominado pós-modernidade, e que tem desencadeado uma mudança paradigmática em todos os níveis de compreensão do ser humano. Foram resgatados os conflitos educacionais da atualidade e apresentados os pressupostos para uma educação pós-moderna, destacando-se, dentre eles, a educação reflexiva, divulgada e proposta por Donald A. Shön, que centra a aprendizagem prática na "reflexão-na-ação", como alternativa para a formação do profissional reflexivo.

DESCRITORES: educação, ensino, aprendizagem

\section{REFLEXIVE EDUCATION IN POST-MODERNITY: A Bibliographical REVIEW}

This is a bibliographical review that aimed at considering teaching at the actual historical moment, denominated postmodernity, and that has resulted in a pragmatic change in all levels of human being understanding. Thus, authors rescued and presented the presuppositions for a post-modern education, emphasizing among them the reflexive education proposed by Donald A. Shön, that is based on practical learning centered in "reflexion-in-action", as an alternative for the formation of a reflexive professional.

\section{LA EdUCACIÓN REFLEXIVA EN LA PÓS-MOdERNIDAD: UNA REVISIÓN BIBLIOGRAFICA}

Se trata de una revisión bibliográfica buscando situar la enseñanza en el momento histórico que estamos viviendo, denominado posmodernidad y que ha desencadenado un cambio paradigmatico en todos los niveles de comprensión del ser humano. Fueron rescatados los conflictos educacionales de la actualidad y presentados los presupuestos para una educación posmoderna, destacándose dentro de ellos la educación rflexiva, divulgada y propuesta por Donals A Shon, que centra el aprendizaje práctico en la "reflexión en la acción", como alternativa para la formación del profesional reflexivo.

DESCRIPTORES: Educación, enseñanza, aprendizaje

\footnotetext{
${ }^{1}$ Excerto de tese de doutorado apresentada à Escola de Enfermagem de Ribeirão Preto da Universidade de São Paulo, Centro Colaborador da OMS para o desenvolvimento da pesquisa em enfermagem, em maio de 2001; ${ }^{2}$ Doutor em Enfermagem Fundamental, Docente da Fundação Educacional de Fernandópolis, e-mail: gomes@acif.com.br; ${ }^{3}$ Professor Doutor da Faculdade de Filosofia, Ciências e Letras de Ribeirão Preto da Universidade de São Paulo, e-mail: casagrande@netsite.com.br
} 


\section{INTRODUÇÃO}

O momento histórico que estamos vivendo, denominado de "pós-modernidade", pode ser entendido como uma crise que está desencadeando uma mudança paradigmática em todos os níveis de compreensão do ser humano. O mundo moderno, de certeza e ordem, tem sido substituído por uma cultura de incertezas e indeterminação.

Enfocando-se esse momento de crise na área da educação, constata-se que a racionalidade técnica - que se trata de uma concepção epistemológica da prática, herdada do positivismo e, segundo a qual, a atividade profissional é sobretudo instrumental, dirigida para a solução de problemas mediante a aplicação rigorosa de teorias e técnicas científicas ${ }^{(1)}$ - que ainda predomina na maioria das escolas, já não atende às reais necessidades para a adequada formação dos jovens da cultura pósmoderna, com os quais temos nos deparado no desempenho de nossa função docente.

Parece claro que as escolas, em geral, e as da área da saúde por conseguinte, ponham-se a pensar sobre os rumos da formação de profissionais no novo século, haja vista que o ensino nessa área é tradicionalmente voltado à racionalidade técnica, tão contestada nos dias atuais. Referimo-nos aos cursos da área da saúde, pelo fato de atuarmos como docentes em um Curso de Graduação em Enfermagem, que, como os demais, está requerendo ajustes dos aparelhos formadores, sob pena de que os egressos da escola não se encaixem às novas demandas geradas na atualidade.

Decorrente disso, a necessidade atual que se apresenta, em relação ao ensino superior, é a formação de profissionais flexíveis e críticos, aptos para a inserção em diferentes setores profissionais e para a participação no desenvolvimento da sociedade brasileira.

Preocupadas em proporcionar um ensino de qualidade aos nossos alunos, compreendemos que devemos buscar novas formas de ensino que contemplem e estimulem o desenvolvimento do espírito científico e do pensamento reflexivo, como características essenciais para a formação profissional, visando atender às exigências contemporâneas.

\section{CONTEXTUALIZANDO HISTÓRICO \\ O MOMENTO}

O momento atual em que nos situamos, corresponde a uma "passagem à pós-modernidade", que se estende desde finais dos anos sessenta e o final da prosperidade do pós-guerra, na economia capitalista mundial. Encontramos, também, como termos que definem esse momento histórico, os seguintes: pós-industrial, póscapitalista, pós-socialista, pós-burguês, pós-econômico, pós bem-estar-social, pós-civilizado ${ }^{(2)}$.

A compreensão do homem como máquina, fruto da visão moderna do mundo, passa a ser questionada pelas novas descobertas da ciência e gera resultados na medicina, na educação, no desenvolvimento da tecnologia, nas organizações empresariais, nas soluções urbanas, etc. Estamos em um momento histórico do qual emerge nova visão de mundo, básica para que o homem construa seus novos tempos.

É hora de reflexão. Conhecer novos paradigmas, e perceber seus múltiplos reflexos nas formas de organização da sociedade humana, é o desafio que se nos apresenta, visto que os enormes problemas globais e inter-relacionais criados pelo paradigma positivista que tem norteado os últimos séculos, tem nos levado, ao lado do desenvolvimento tecnológico, a um afastamento essencial do ser humano ${ }^{(3)}$, tornando-se difícil compreender a nova cultura que emerge do tempo e do espaço, e as transformações relacionadas com formas de conhecimento e experiência no mundo pós-moderno ${ }^{(4)}$.

No novo sistema social que emerge, uma característica distintiva é a de que "informação e conhecimento estão profundamente inseridos na cultura das sociedades (...), e a capacidade mental de trabalho está vinculada à educação e à formação". Daí decorre que "a habilidade de usar (e de alguma maneira produzir) tecnologias de informação converteu-se em uma ferramenta fundamental de desenvolvimento"(5).

O "debate pós-moderno" realizado pelos intelectuais tem provocado pouco consenso, confusão e muita discórdia. $O$ desafio pós-moderno não só constitui um corpo diferente de crítica cultural, mas deve também ser visto como "um discurso contextual que tem desafiado os limites disciplinares específicos em campos, tais como os estudos literários, a educação, a arquitetura, o feminismo, a arte, a sociologia e muitas outras áreas" ${ }^{\prime(4)}$.

A respeito da juventude inserida na cultura pósmoderna, denota-se que a instabilidade e a transitoriedade difundidas de forma característica entre os jovens da faixa etária de 18 e 25 anos, estão inseparavelmente ligadas a um grande número de condições pós-modernas que têm 
provocado um mundo com pouca segurança psicológica, econômica e intelectual para os jovens, visto que o mundo moderno, de certeza e ordem, deu lugar a um planeta no qual o tempo e o espaço são condensados no chamado espaço rápido (speed space) onde os jovens, sem pertencerem a algum lugar concreto, vão vivendo progressivamente esferas culturais e sociais mutáveis, marcadas por uma pluralidade de linguagens e culturas ${ }^{(4)}$.

Nesse contexto, surge o "neo-individualismo" pósmoderno, no qual o sujeito vive sem projetos, sem ideais, a não ser cultuar sua auto-imagem e buscar satisfação aqui e agora, "admirando-se a si mesmo e amando-se perdido na multidão". Massificado pelas engrenagens sociais que o fazem consumidor, ouvinte, telespectador, cliente, paciente, aluno, eleitor e transeunte, o sistema Ihe tira a "a subjetividade que o individua como pessoa (...). Por isso, o jovem de hoje quer dizer a todos que existe como sujeito, como indivíduo na massa social”(6).

Nessa perspectiva, os valores já não nascem a partir de uma pedagogia modernista de fundamentalismo e verdades universais, nem de discursos tradicionais baseados em identidades fixas e com uma estrutura final. Para muitos jovens, "o sentido já está esgotado, a mídia tem se convertido em um substituto da experiência, e o que constitui o entendimento apresenta-se como um mundo de diferenças descentradas e dispersas, de deslocamento e de intercâmbios". Portanto, para muitos jovens, entrar na idade adulta, no século XXI, significa perder a esperança e tentar adiar o futuro, em vez de aceitar o desafio moderno de tentar construí-lo(4).

\section{CONFLITOS EDUCACIONAIS DA ATUALIDADE}

Com base nas repercussões decorrentes da influência da cultura pós-moderna em todas as instâncias da vida em sociedade, podemos afirmar que, certamente, estamos em um momento de crise, se considerarmos que os valores antigos já não resolvem os problemas existentes, e os valores novos não estão ainda firmes e com resultados que atendam às expectativas dos indivíduos.

Se nos reportarmos especificamente à influência da cultura pós-moderna na educação, poderemos perguntar: De que forma essas modificações afetam a escola e a educação como um todo? Como se manifestam essas influências no dia-a-dia da escola? De que forma influenciam na disciplina dos alunos? O que essa cultura tem a ver com o currículo da escola como um todo? Como se sente o professor inserido nesse contexto? E o aluno?

Ao situar a escola no contexto atual, verifica-se que ela está no meio de um turbilhão de fatos, acontecimentos, situações, fenômenos, episódios, processos sociais, políticos, econômicos, culturais, éticos, religiosos e outros mais, sofrendo, terrivelmente, os impactos das mudanças cada vez mais rápidas e vertiginosas da pós-modernidade. Sua estrutura é "pesada e lerda" para acompanhar a evolução social, no ritmo voraz das sociedades pós-industriais ${ }^{(6)}$.

Na tentativa de explanar sobre os conflitos que se instalam em âmbito educacional e condicionam toda a dinâmica de relações humanas e poder que se estabelecem nas escolas, surgem, no cenário da pedagogia, críticos de várias correntes filosóficas que muito têm contribuído para propiciar aos educadores a compreensão dos problemas que eles têm enfrentado junto à uma geração pós-moderna de jovens, fator que lhes lança um desafio para o adequado desempenho das funções docentes, voltadas ao processo de ensino e aprendizagem.

Para enfrentar essa problemática - a do conflito entre as escolas e seus educadores e a geração de jovens da cultura pós-moderna -, os educadores, ao desempenharem suas funções docentes, terão que converter o pedagógico em algo mais político, indicando tanto as condições por meio das quais educam, como o significado da aprendizagem para uma geração que está experimentando a vida em um sentido totalmente diferente das representações oferecidas pelas versões modernas da escola, as quais ainda predominam no cenário educacional $^{(4)}$.

Alguns estudos têm procurado mostrar que a origem desses conflitos nas escolas decorre do fato de que, de um lado, os alunos reclamam que não são respeitados e que as escolas são muito autoritárias. De outro, os professores dizem que os alunos não têm limites e só vêem a escola como um local para encontrar os amigos. Esse desencontro de percepções e visões ${ }^{(7)}$ foi mostrado por uma pesquisa feita pelo Cenpec (Centro de Estudos e Pesquisa em Educação, Cultura e Ação Comunitária) e a organização não-governamental Literis, revelando que "o jovem se sente excluído do projeto pedagógico da escola. Ele se lembra muito pouco do que ensinaram a ele, (...) não se lembra de um livro que tenha lido por orientação de um professor, ou de um trabalho 
interessante que tenha feito". Em outras palavras, a pesquisa mostra que os jovens têm uma experiência escolar limitada, sentem que não pertencem àquele ambiente, e, por isso, a escola deixa de ser um local onde eles podem se expressar e ser o que são.

A indisciplina, que predomina no ambiente escolar, tem como causas "vários aspectos que vão da falta de dinamismo, criatividade de alguns professores, passando pela falta de interesse dos conteúdos ministrados, até falta de educação, de respeito, de consciência de seus limites, por parte dos alunos", já que os jovens pósmodernos possuem uma mentalidade, uma cultura da indisciplina, do valor positivo da transgressão à ordem estabelecida. Para esses jovens, não há referenciais, não há por que segui-los. A vida é feita de fragmentos, de momentos de prazer, de satisfação imediata, de emoções fortes, de sensações chocantes, sem fronteiras e sem bandeiras, sem limites éticos ou morais ${ }^{(6)}$.

Decorre desse quadro a falta de respeito para com o professor, expressa por manifestações, tais como: o riso cínico, a mentira fria, o vandalismo individual acobertado pelo grupo, o apoio tácito ou ostensivo aos que enfrentam e "peitam" o professor, retratando a mentalidade que se espalha entre os jovens de que o bem que vale é o seu próprio bem individual. Predomina, na juventude, o individualismo, a falta de referenciais, de objetivos, de limites, de fronteiras, o desprezo pelo senso comum, pela cultura histórica, e a ausência de ideal, indiferença e apatia ${ }^{(6)}$.

É o neo-individualismo pós-moderno que faz o aluno negar-se a discutir um tema, não se mobilizar, apesar de todos os esforços competentes do professor, porque defende a idéia de que cada um deve ter sua própria idéia e não há por que confrontá-la com a dos outros.

Ainda referindo-se a esses conflitos educacionais, considera-se que o desencontro entre professores e adolescentes decorre de dois tipos de processos. Em parte, ele reflete questões sociais mais abrangentes, ligadas à sociedade moderna, em que as relações sociais tendem a se fragmentar. Além disso, ele decorre de características da própria escola, que é uma instituição que se estrutura sobre mecanismos de exclusão, por ainda ser muito hierarquizada e funcionar segundo um código de normas rígido, que acaba excluindo o aluno em vez de incorporar o seu universo de vida, de pensamento ${ }^{(7)}$.

A perspectiva comunicativa, que surge em oposição à tradicional visão encontrada nas escolas, afirma a necessidade de atitudes críticas e transformadoras, que superem as desigualdades criadas pelo modelo dual da sociedade da informação, através do diálogo e do consenso entre todas as pessoas envolvidas.

Apesar de, inquestionavelmente, estarmos em um momento de crise, "nem tudo está errado... Aliás, há imensos valores e aspectos positivos no contexto da pósmodernidade em que vivemos. (...) A própria crise contém os valores que levam o homem a superá-la. Precisamos saber resgatá-los e dinamizá-los de forma adequada"(6).

As considerações apresentadas acerca dos conflitos educacionais da atualidade, levam-nos a concluir que, enquanto educadores, estamos num momento de decisões, numa transição entre um mundo que se vai e um mundo novo que surgirá dos fundamentos que agora firmarmos. Incorporar na educação esses valores apontados, torna-se, para os educadores comprometidos com a superação da crise no ensino, o principal desafio a ser enfrentado. Pelo fato de termos feito a opção para sermos um desses educadores, recortamos, na literatura, considerações relevantes sobre os pressupostos que norteiam a educação pós-moderna, necessária aos dias atuais.

\section{PRESSUPOSTOS PARA UMA EDUCAÇÃO PÓS- MODERNA}

Para sintetizar a visão do paradigma pós-moderno, julga-se que negativamente, "o pós-moderno é um estilo de pensamento desencantado da razão moderna e dos conceitos a ela vinculados. Não crê na razão autônoma e fundante, que dá sentido ao homem e ao seu comportamento". Positivamente, a pós-modernidade é uma nova concepção da razão e da racionalidade, não como elemento central ou único, mas abrindo-se à riqueza e à heterogeneidade da vida, irredutível a toda forma de pretensão universalista. $\mathrm{O}$ "pós-moderno pleiteia que o homem seja verdadeiramente livre e autônomo para determinar sua própria história e sua vida"(8).

Decorrente dessas idéias, torna-se indispensável um processo de discernimento e uma lúcida formação da liberdade, visando oferecer à educação os referenciais mais importantes para capacitar educadores e educandos a viver em um mundo como o nosso, secularizado e pluralista, científico e tecnológico, fragmentado e mutante, na experiência da crise de tudo isso( ${ }^{(8)}$. 
Acredita o autor que, pelo exercício do discernimento e da liberdade, a educação de hoje não será atenção acrítica e dócil aos modismos de último grito, lançados e explorados pelo mercado. Tampouco será uma submissão rígida e passiva aos ditames de uma tradição, já incompatível com os parâmetros reais de nosso mundo concreto. Pelo contrário, tornarão possível aprimorar e levar adiante elementos fundamentais da tradição, tecida ao longo do tempo e da história, permitindo visões realistas e prospectivas que, ao mesmo tempo, iluminam o presente e constroem o futuro com fecunda criatividade. "Educar não será um esforço enciclopédico para estocar informação no cérebro ou no computador. Educar será capacitar pessoas para situar-se responsavelmente no mundo: será viver a partir da história, será criar história"(8).

Partilhar mais as idéias, perceber-lhes melhor o contorno concreto do dia-a-dia, insistir numa metodologia de trabalho pedagógico que valorize a tomada de posição, levando os alunos a emitir opinião sobre os temas, discutir aspectos positivos ou negativos, as dimensões sociais, políticas, éticas, culturais, religiosas, econômicas e outras, sobre os fatos, situações, personagens, acontecimentos, etc., são caminhos que possibilitam a formação de cidadãos capazes de pensar e planejar um processo para transformar a sociedade ${ }^{(6)}$.

Constatação da premente necessidade de transformações filosóficas e pedagógicas que venham atender às expectativas da cultura pós-moderna, pode ser representada, no Brasil, pela revolução educacional desencadeada oficialmente com a Lei N 9.394, de 20 de dezembro de $1996^{(9)}$, que estabeleceu as diretrizes e bases da educação nacional. Nessa nova L.D.B. (Lei das Diretrizes Básicas), a educação superior tem, como finalidades principais, formar indivíduos aptos para a inserção em setores profissionais, para a participação no desenvolvimento da sociedade brasileira e estimular o desenvolvimento do espírito científico e do pensamento reflexivo.

Atendendo à nova L.D.B., surgem as diretrizes curriculares que fornecem as bases filosóficas, conceituais, políticas e metodológicas que definem um conjunto de habilidades e competências de uma área de conhecimento, permitindo a flexibilização dos currículos de graduação e, conseqüentemente, permitindo a implementação de projetos pedagógicos inovadores, os quais norteiem as experiências de aprendizagem que capacitem o aluno a trabalhar com o específico, partindo de uma estrutura sólida, fundamental, de sua área de conhecimento. Assim, os profissionais formados a partir das novas propostas das diretrizes curriculares serão "mais críticos, reflexivos, dinâmicos, ativos, adaptáveis às demandas do mercado de trabalho, aptos a aprender a aprender, a assumir os direitos de liberdade", enfim, atender às tendências do mundo globalizado, bem como às necessidades de desenvolvimento do país ${ }^{(10)}$.

Sem dúvida, estamos vivendo um momento de transição paradigmática onde os conceitos voltados ao ensino, até então vigentes, não respondem às necessidades postas por um presente desestabilizador e um futuro incerto. "Se há alguma clareza no horizonte educacional, ela aponta para a urgência de se redefinir o papel das instituições escolares, formando pessoas para atuarem em cenários que, talvez, nem possam ser entrevistos"(11).

Ancoradas nesses pressupostos, apresentamos, na seqüência do texto, uma abordagem voltada à educação dos novos tempos, que consideramos de vital importância para nortear as ações pedagógicas adequadas e necessárias para a formação do ser humano.

\section{A EDUCAÇÃO REFLEXIVA}

Se hoje se fala em educar as pessoas como o mundo precisa, é importante que se compreenda que esse processo, necessariamente, não será uma educação para o conformismo, mas voltada à liberdade e à autonomia. Surge, pois, no cenário educacional, uma nova cultura, denominada "cultura reflexiva", que representa a criação de uma nova postura em face às situações educativas, quando as práticas tradicionais dos professores apresentaram-se como não respondentes aos problemas presentes $^{(12)}$.

A origem da "cultura reflexiva" no ensino tem, como marco, a Teoria da Indagação, de John Dewey (1859-1952), que foi um filósofo, psicólogo e educador norte-americano que influenciou, de forma determinante, o pensamento pedagógico contemporâneo. Suas obras foram fundamentais para que o movimento da Escola Nova tomasse impulso e se propagasse por quase todo o mundo, sendo citado, por muitos, como o pai da educação progressista. O enfoque que dava à pedagogia era voltado à experiência prática, sendo, por isso, às vezes, chamada de fazendo e aprendendo. 
A experiência concreta da vida, para Dewey, surge sempre ao nos depararmos com problemas, e a educação deve tomar para si essa condição, enfrentando-a com uma atitude ponderada, cuidadosa, persistente e ativa, para garantir o melhor desenvolvimento do educando. Segundo ele, diante de algum problema, o ato de pensar deve ancorar-se nos seguintes pontos: 1) uma necessidade sentida, ou seja, o problema; 2) a análise da dificuldade; 3) as alternativas de solução do problema; 4) a experimentação de várias soluções, até que o teste mental aprove uma delas, e 5) a ação como prova final para a solução proposta, que deve ser verificada de maneira científica $^{(12)}$

Dewey argumenta que o processo de reflexão inicia-se no enfrentamento de dificuldades de difícil superação, e a instabilidade gerada perante essas situações leva o indivíduo a analisar as experiências anteriores. Sendo uma análise reflexiva, envolverá a ponderação cuidadosa, persistente e ativa das suas crenças e práticas à luz da lógica da razão que a apóia. Nessa reflexão, estarão envolvidas, com a mesma intensidade, a intuição, a emoção e a paixão, e a lógica da razão e da emoção estão atreladas entre si e caracterizam-se pela visão ampla de perceber os problemas. As pessoas com ações reflexivas não ficam presas a uma só perspectiva, examinam, criteriosamente, as alternativas que a elas se apresentam como viáveis, como também aquelas que Ihes parecem mais distantes da solução, com o mesmo rigor, seriedade e persistência ${ }^{(12)}$.

Dentre os adeptos da "cultura reflexiva" voltada à educação, Lawrence Stenhouse, um educador inglês que, na década de setenta, dedicou toda sua carreira à luta por reconhecer no professor uma postura de produtor de conhecimentos sobre as situações vividas em sua prática docente, e não apenas como simples reprodutor e executor de conhecimentos previamente estabelecidos, definiu, como princípios para o processo pedagógico, entre outros: tratar, em aula, questões controvertidas; trabalhar o diálogo, e não a instrução, como atividade central da aula; não usar, por parte dos professores, a autoridade para apresentar seus pontos de vista como se fossem verdades objetivas; respeitar pontos de vista divergentes; assumir, por parte dos professores, a responsabilidade pela qualidade e nível de aprendizagem ${ }^{(12)}$.

A partir de Stenhouse, a Pedagogia, concebida como "a intenção de desenvolver princípios de procedimentos de forma prática concreta", constitui necessariamente um processo reflexivo, pois a mudança curricular satisfatória depende do desenvolvimento das capacidades de auto-análise e reflexão dos professores. Baseado nessa concepção, elaborou sua idéia, agora em voga, de "professor como pesquisador".

O enfoque dado à educação na "cultura reflexiva" remete-nos aos pressupostos defendidos por Paulo Freire, importante educador crítico que, em sua obra "Pedagogia da Autonomia"(13), traz como temática central a questão da formação docente ao lado da reflexão sobre a prática educativo-progressista, em favor da autonomia do ser dos educandos. Para isso, o educador deve exercer uma pedagogia fundada na ética, no respeito à dignidade e à própria autonomia do educando.

No progressivo desenvolvimento da "cultura reflexiva", ainda em processo, um dos autores que teve maior peso na difusão do conceito de "reflexão", foi Donald Schön, filósofo e pedagogo norte-americano que tem centrado seus estudos e suas preocupações nos problemas de aprendizagem, nas organizações e na eficácia profissional.

Os pressupostos de Shön, apoiados na herança do pensamento de Dewey acerca da reflexão aplicada às questões educacionais, começaram a ser difundidos por meio de seus livros "The Reflective Practitioner" (14) e "Educating the Reflective Practitioner" ${ }^{\text {"(15) }}$, que contribuíram para popularizar as teorias sobre a epistemologia da prática (termo utilizado para referir-se ao estudo das teorias do conhecimento, adquirido através de atividades práticas).

O autor segue uma linha de argumentação centrada no saber profissional, tomando como ponto de partida a "reflexão-na-ação", que é realizada ao se defrontar com situações de incertezas, singularidade e conflito, sempre amparado por um tutor de aprendizagem prática, numa relação mediada pelo diálogo entre tutor e estudante, onde "a atitude de dizer e demonstrar do tutor combina-se com a atitude de escutar e imitar do estudante e, nesse sentido, uma "reflexão-na-ação" de ambos, o que implica aprender a prática de um prático, praticando. Nesse processo efetiva-se a aprendizagem, o que é chamado por Shön de um círculo vicioso de aprendizagem"(16).

Os pressupostos propagados por Donald Shön comentam que ele centra sua concepção de desenvolvimento de uma prática reflexiva, para a formação de um profissional reflexivo, em três idéias centrais: o "conhecimento-na-ação", a "reflexão-na-ação" e a "reflexão sobre a reflexão-na-ação". 
O "conhecimento-na-ação" traz consigo um saber que está presente nas ações profissionais as quais, por sua vez, vêm carregadas de um "saber escolar", entendido como um tipo de conhecimento supostamente possuído pelos profissionais; uma visão dos saberes profissionais como fatos e teorias aceitos ${ }^{(15)}$. É esse "saber escolar" que possibilita ao profissional transitar no seu meio e poder agir, por possuir "um conhecimento na ação". Porém, o "saber escolar" também se caracteriza por estar colado a um certo modo de enfrentamento das situações do cotidiano e por revelar um conhecimento espontâneo, intuitivo, experimental. O conhecimento, portanto, está na ação em si, e o revelamos por meio de ações espontâneas e habilidades.

Shön considera que o "conhecimento-na-ação" pode ser compreendido, também, como conhecimento técnico ou solução de problemas, ou seja, é o componente inteligente que orienta toda a atividade humana e manifestase no "saber fazer".

A "reflexão-na-ação", para Shön, está em relação direta com a ação presente, ou seja, com o "conhecimento-na-ação", e significa produzir uma pausa para refletir - em meio à ação presente, um momento em que paramos para pensar, para reorganizar o que estamos fazendo, refletindo sobre a ação presente. Para ele, se observarmos e refletirmos sobre nossas ações, podemos descrever um conhecimento que nelas está implícito. Então, mediante a observação e a reflexão, podemos descrever e explicitar essas ações e, para isso, posicionamo-nos diante do que desejamos observar, podendo, então, encontrar novas pistas para a solução dos problemas que se nos apresentam ${ }^{(15)}$.

$\mathrm{Na}$ vida quotidiana, freqüentemente pensamos sobre o que fazemos ao mesmo tempo em que atuamos. Para Shön, é esse componente que representa a "reflexãona-ação", ou seja, o processo de diálogo com a situação problemática que exige uma intervenção concreta. Considera que, nesse processo, o profissional envolvido com a situação, encontra-se constrangido pelas pressões espaciais e temporais e pelas solicitações psicológicas e sociais do cenário em que atua. Portanto, "é um processo de reflexão sem o rigor, a sistematização e o distanciamento requerido pela análise racional, mas com a riqueza da captação viva e imediata das múltiplas variáveis intervenientes e com a grandeza da improvisação e criação"(1).

Essa "reflexão-na-ação" só se desencadeia quando não encontramos respostas às situações inesperadas que emergem da ação presente e, então, posicionamo-nos criticamente perante o problema e questionamos as estruturas de suposição do "conhecimento-na-ação". Pensamos de maneira crítica sobre o pensamento que nos levou a essa situação-surpresa e, durante o processo, podemos reestruturar estratégias de ação: pela compreensão do fenômeno ou pela maneira de formular o problema. Shön considera que "é impossível aprender sem ficar confuso".

Esse distanciamento da ação presente, para refletirmos, é um movimento que pode ser desencadeado sem gerar, necessariamente, uma explicação verbal, uma sistematização teórica. Todavia, ao produzirmos uma descrição verbal, isto é, uma reflexão sobre nossa reflexão da ação passada, podemos influir, diretamente, em ações futuras, colocando em prova uma nova compreensão do problema. Esse momento é designado por Shön como o da "reflexão sobre a reflexão-na-ação", que é caracterizado pela intenção de se produzir uma descrição verbal da "reflexão-na-ação". É necessário, ainda, a capacidade de se refletir acerca da descrição resultante, podendo-se gerar modificações em ações futuras, ou seja: quando se reflete sobre a "reflexão-na-ação", julgando e compreendendo o problema, pode-se imaginar uma solução para ele.

A "reflexão sobre a reflexão-na-ação" pode ser considerada como a análise que o indivíduo realiza a posteriori sobre as características e processos da sua própria ação. É a utilização do conhecimento para descrever, analisar e avaliar os vestígios deixados na memória por intervenções anteriores ${ }^{(1)}$. Para o autor, "na reflexão sobre a ação, o profissional prático, liberto dos condicionamentos da situação prática, pode aplicar os instrumentos conceituais e as estratégias de análise no sentido da compreensão e da reconstrução da sua prática".

Esses três processos descritos - "o conhecimentona-ação", "a reflexão-na-ação" e a "reflexão sobre a reflexão-na-ação" - constituem o "pensamento prático" do profissional, com o qual enfrenta as situações "divergentes" da prática. Esses processos não são independentes, mas, sim, completam-se entre si para garantir uma intervenção prática racional.

\section{CONSIDERAÇÕES FINAIS}

Comprometidas com uma educação que atenda aos pressupostos da pós-modernidade, consideramos ter 
encontrado, nos pressupostos de Donald Shön, uma alternativa para que a formação profissional possa ser implementada de forma que desenvolva as habilidades reflexivas, tão necessárias aos dias atuais.

No processo prático de formação de profissionais reflexivos, proposto por Shön, entendemos que, embora o pensamento prático do professor não possa ser ensinado ao aluno, ele pode ser aprendido desde que, por meio de uma reflexão conjunta e recíproca entre o aluno e o professor/tutor, se faça e se reflita na ação prática e sobre ela. Uma vez que não é possível ensinar o pensamento prático, a figura do supervisor ou tutor universitário adquire uma importância vital e, portanto, deve adequar-se às reais necessidades do aluno, no seu processo de aprendizagem.

Nas situações decorrentes da prática, não existe um conhecimento profissional para cada caso-problema, que teria uma única solução correta. O profissional competente atua refletindo na ação, criando uma nova realidade, experimentando, corrigindo e inventando por meio do diálogo que estabelece com essa mesma realidade. $\mathrm{Na}$ base dessa perspectiva, que confirma o processo de "reflexão-na-ação" do profissional, é que se encontra uma concepção construtivista da realidade confrontada.

No processo de ensino e aprendizagem do futuro profissional reflexivo, as percepções, apreciações, juízos

\section{REFERÊNCIAS BIBLIOGRÁFICAS}

1. Gómez AP. O pensamento prático do professor: a formação do professor como profissional reflexivo. In: Nóvoa A, organizador. Os professores e a sua formação. Lisboa (Portugal): Publicações Dom Quixote; 1992. p.95-114.

2. Flecha R. As novas desigualdades educativas. In: Castells M, Flecha R, Freire P, Giroux H, Macedo M, Willis P. Novas perspectivas críticas em educação. Porto Alegre (RS): Artes Médicas; 1996. p.33-52.

3. Garcia LC. Nasce mais um filho da Unipaz. Unipaz Jornal 1998 julho; (1):2.

4. Giroux $H$. Jovens, diferença e educação pós-moderna. In: Castells M, Flecha R, Freire P, Giroux H, Macedo M, Willis P. Novas perspectivas críticas em educação. Porto Alegre (RS): Artes Médicas; 1996. p.63-85.

5. Castells M. Fluxos, redes e identidades: uma teoria crítica da sociedade informacional. In: Castells M, Flecha R, Freire P, Giroux H, Macedo M, Willis P. Novas perspectivas críticas em educação. Porto Alegre (RS): Artes Médicas; 1996. p.332.

6. Cruz CHC. Influências da pós-modernidade na escola. Rev de Educação AEC 1993 out/dez; 22(89):99-125.

7. Avancini M. Pesquisa investiga raízes da indisciplina. Folha de São Paulo 199808 maio: Cad. 2; 3. e crenças do professor acerca dessa realidade são um fator decisivo de orientação no processo de produção de significados, que constitui, para o aluno, o fator mais importante do processo de construção da realidade profissional. Portanto, o diálogo entre o professor e o aluno constitui princípio de procedimento que leva ao conhecimento crítico do ponto de vista educativo e que estabelece uma relação forte com o processo de levar a pensar, ao invés de apenas se preocupar com o resultado do processo.

Acreditamos que a formação do profissional enfermeiro possa ser implementada baseando-se no modelo proposto por Shön, visto que, em campos de aprendizagem prática, o aluno de enfermagem desenvolve a sua aprendizagem sempre sob a supervisão de um professor enfermeiro, já experiente, que exerce uma função que poderia ser chamada de "tutoria". Cabe a esse supervisor ou tutor, responsável pela formação prática e teórica do futuro profissional, tornar-se capaz de atuar e refletir sobre a sua própria ação como formador, percebendo que sua intervenção é uma prática de segunda ordem, um processo de diálogo reflexivo com o aluno, sobre as situações profissionais que ele, futuramente, irá desempenhar.

Esperamos, com este texto, ter contribuído para o despertar de novas idéias que venham a ser utilizadas didaticamente, para a formação de profissionais reflexivos.

8. Azevedo MC. Não-moderno, moderno e pós-moderno. Rev de Educação AEC 1993 out/dez; 22(89):19-35.

9. Lei de Diretrizes e Bases da Educação Nacional de 1996, Pub. L. nº 9394 (20 de dezembro, 1996).

10. Utyama IKA, Martins JT. L.D.B e diretrizes curriculares: aplicação no currículo integrado do curso de enfermagem da UEL. Rev Olho Mágico 1999 outubro; 5(20):8-9.

11. Valente SMP. Do currículo às diretrizes curriculares. Rev Olho Mágico 1999 outubro; 5(20):6-7.

12. Pereira EMA. Professor como pesquisador: o enfoque da pesquisa-ação na prática docente. In: Geraldi CMD, Fiorentini $D$, Pereira EMA, organizadores. Cartografias do trabalho docente: professor(a)-pesquisador(a). Campinas (SP): Mercado de Letras; 1998. p.153-182.

13. Freire P. Pedagogia da autonomia. $11^{a}$ ed. Rio de Janeiro (RJ): Paz e Terra; 1996.

14. Shön DA. The reflective practitioner. New York (EUA): Basic Books; 1983.

15. Shön DA. Educating the reflective practitioner. New York (EUA): Jossey-Bass; 1987.

16. Campos S, Pessoa VIF. Discutindo a formação de professoras e professores com Donald Shön. In: Geraldi CMG, Fiorentini D, Pereira EMA, organizadores. Cartografias do trabalho docente: professor(a)-pesquisador(a). Campinas (SP): Mercado de Letras; 1998. p.183-206. 